\title{
Current Situation and Reform Approaches of Mandarin Teaching in Chinese Universities
}

\author{
Shi-min Yang ${ }^{1}$, Qiao-ling Dai ${ }^{2}$ \\ ${ }^{1}$ JiangXi Normal University Science And Technology College, Jiangxi Province, China \\ ${ }^{2}$ JiangXi Vocational Academy of Art, JiangXi Province, China
}

\begin{abstract}
Colleges and universities are important platforms to promote Mandarin. However, due to many constraints, Mandarin teaching hasn't yielded a good result. And some of its problems have been identified by the author through research. Therefore, it's imperative to explore new approaches of teaching reform so that students of all levels can improve their Mandarin proficiency effectively, thus bringing about huge progress in Mandarin teaching as a whole.
\end{abstract} reform

Index Terms - Colleges and universities; Mandarin; teaching

\section{Introduction}

China is a multinational country with a large population. Dialect varies greatly from one area to another. Chinese college and university students come from many dialect areas, thus different groups speak different dialects. However, this difference produces an adverse impact on Mandarin teaching. In some colleges or universities, one class has multiple dialect systems. Since pronunciation and grammar differ much from dialect to dialect, and most dialects are extremely different from Mandarin, Mandarin teaching in Chinese colleges and universities becomes all the more complicated.

Mandarin is a very practical language discipline, and it is special compared with other specialized courses. The Mandarin proficiency exam not only serves as an important tool to test Mandarin teaching in colleges and universities, but helps improve students' ability to speak Mandarin. However, due to expansive admission sources and outdated teaching methods, the current Mandarin teaching in Chinese colleges and universities hasn't met the goal of raising students' Mandarin proficiency. Therefore, it's a pressing task to carry out Mandarin teaching reform in Chinese colleges and universities.

\section{Problems with Mandarin Teaching}

Mandarin has been taught in Chinese colleges and universities for nearly three decades. Abundant teaching experience has been accumulated, and contributions have been made to raising students' Mandarin proficiency. However, as the scale of admission grows and more and more new students come from other provinces, the defects of conventional classroom teaching of Mandarin begin to emerge. Some of them have severely impacted teaching results.

\section{A. The Teaching Mode Lacks Pertinence}

In recent years, conventional Mandarin teaching modes face enormous pressure from the growth of admission quota for other provinces. Usually, a normal class includes students from multiple dialect areas, and many dialects are complex. In this case, the single teaching mode is far from meeting the demand of raising students 'Mandarin proficiency.

In present Mandarin teaching of colleges and universities, students of the same major are put into the same class (conventional class-setting system), or students are given the freedom to choose the classes they prefer. The number of students in each class is 40-60 on average, and classroom lecturing dominates the teaching process. This method leads to a spoon-feed result with teachers playing the leading role. The conventional big-class teaching doesn't take into account the difference of Mandarin proficiency and dialect phonetic systems among students; hence, the result is not satisfactory. In conclusion, Mandarin teaching should move in a systematic and multi-dimensional direction that it accommodates the needs of students from different areas and of different proficiency and it is connected with coaching.

For example, the author analyzed the situation of Mandarin teaching in a university of Jiangxi Province. This university locates in northern Jiangxi and borders on Zhejiang, Anhui and Fujian. The frequently spoken dialects in the university include Gan (Jiangxi) Dialect, Hui (Anhui) Dialect, Wu (Shanghai) Dialect, Hakka and Southern Fujian Dialect. Local dialects in Jiangxi Province are very different from each other in terms of pronunciation. Yingyi dialect area alone includes 12 cities and counties. And Hui Dialect also contains Wuyuan Dialect and Dexin Dialect (both places locate in Jiangxi). Most often, students in a class come from different areas, thus a wide range of dialects are spoken. This causes much difficulty for Mandarin teaching in this university. If a teacher focuses only on the features and pronunciation of a certain dialect, students from other areas will hardly master the learning laws of Mandarin since their language base is different. That's why the study results differ so much as to students from different areas.

\section{B. The Course Design is not Scientific}

Course design means defining reasonable course structure and content. Through Mandarin course design, teaching goals can be fully demonstrated in teaching process, and teaching quality can be further improved. In reality, however, the Mandarin teaching content in many colleges and universities is not comprehensive and targeted; students of different aptitude are hardly taught in different approaches. Meanwhile, although the Mandarin textbooks are authoritative, they haven't been 
revised with the times. Also, they attach too much importance to the Mandarin grade test, which makes it difficult to raise students' Mandarin proficiency fundamentally. Moreover, some teachers seldom touch upon difficult content in the textbooks, or they simply teach whatever they like. Mandarin courses are limited in colleges and universities, usually no more than 40 class hours each term. Under such circumstances, a good teaching result is almost impossible.

\section{The Mandarin Training is not Enough}

So far, China hasn't established systematic and sound Mandarin teaching theories. The teaching methods lack innovation, and the teaching modes are in confusion, with little attention on the intensive training of Mandarin by students themselves. Some colleges or universities open Mandarin training courses only for language majors. As for non-language majors, they are only taught basic theories of Mandarin. Some even don't offer any systematic Mandarin training since they believe classroom guidance on oral language is the same as Mandarin training. For others, although Mandarin training courses are opened, teachers remain the major player in class while students seldom open their mouths. In Mandarin teaching, to accommodate the language difference of dialect areas, teachers have to spend much energy comparing and analyzing the difference among dialects and the difference between these dialects and Mandarin. Moreover, they have to cover as much information as possible since students have different proficiency, which requires longer teaching hours. Due to this specailty of Mandarin teaching, little time is left for students to practise in class, thus a good result is nearly impossible.

\section{New Reform Approaches of Mandarin Teaching in Chinese Colleges and Universities}

From the analysis above, it is concluded that Mandarin teaching in Chinese colleges and universities faces many difficulties since the conventional classroom teaching lacks pertinence and it can't accommodate the needs of students from different areas and of different proficiency. To crack the hard nut, it is imperative to conduct teaching activities that are based on area and proficiency and that combines teaching and training.

\section{A. Dividing Classes based on Differences}

Language representation differs from one area to another, while it is very close in the same region. Therefore, dividing classes by area will make Mandarin education more targeted. A reasonable Mandarin proficiency assessment system can be established based on different dialect areas of students. The proficiency will be assessed in a multi-dimensional manner, and the results will serve as a reference for dividing classes. This teaching pattern overcomes the defects of conventional big-class teaching since it highlights the differences of Mandarin proficiency among students. In dividing classes, those who come from adjacent dialect areas and who have equal language foundations will be put into the same class. And selective Mandarin courses can also be opened to meet the need of different students. When classes are divided, teachers can design targeted teaching content based on the proficiency gap of their students, so as to achieve balanced improvement in the class. For students with a standard Mandarin pronunciation, teachers should make more efforts to improve their expression and public speaking. For students with intermediate Mandarin skills, teachers should attach more importance to language rheology training, for example, reading model essays to help correct the pronunciation of their students. For students who have many problems with Mandarin study, they can be asked to read and recite poems or tongue twisters so that gradually, their false pronunciations of initials and finals can be corrected. This tailored class-dividing and teaching pattern not only embodies the gap of language foundations among students, but also helps achieve a balanced improvement for them, thus everyone will study and practice Mandarin and value its importance.

\section{B. Designing Multiple Levels of Teaching Goals}

Teachers can design multiple levels of teaching goals in accordance with the general goal for Mandarin teaching in Chinese colleges and universities and the requirements of Mandarin proficiency test, so as to provide guidance for teaching result assessment and student self-study. Teaching goals can also be based on the pass rate of Mandarin proficiency test. Students who fail to pass Band 2-B should be the key training targets since their Mandarin foundations are weak and they tend to meet difficulties in study very easily. Meanwhile, different teaching content should be designed according to the areas students come from, with Band 2 (B) as the priority target. In addition, teachers should strengthen the training of basic knowledge on students. This should be done step by step, from syllables to words and sentences, and then to paragraphs and texts, and finally to daily communication. At the same time, teachers should make their students more interested in learning Mandarin and encourage them to speak Mandarin. For students who rank between Band 2-A and Band 2-B, they should also be taught by area with Band 2-A as the major teaching target. Teachers should guide students to identify their problems with pronunciation, compare their pronunciation with standard Mandarin pronunciation, find out the differences and conduct targeted training. If the students have passed Band 2-A, it is unnecessary to teach them by area. In this case, the teaching priority should be to correct their language defects and help them feel and grasp language sense so that they can communicate in Mandarin fluently and vividly.

\section{Combining Teaching and Coaching and Putting Knowledge to Use}

Mandarin teaching in colleges and universities should combine teaching and coaching. Teachers should not only teach well, but also follow and monitor the exercise and review of students. In particular, they should coach those students with weak Mandarin foundations after class. Besides, more Mandarin practice courses should be opened to offer more opportunities for students to practice or apply Mandarin. 
Some upperclassmen who score high in Mandarin proficiency test can be invited as the tutors for low grade Mandarin classes. They can use their spare time to coach the students of lower Mandarin proficiency, at least 4 hours each week. The Mandarin proficiency assessment system should include the points scored in practice so that students can take the initiative in speaking Mandarin in daily life, genuinely master Mandarin skills and improve Mandarin proficiency.

\section{Conclusion}

To improve Mandarin teaching in Chinese colleges and universities, it is imperative to optimize the design of course structure and content. Students should be divided and taught by dialect area with different targets for different proficiencies, so as to provide solid guarantee for effective teaching. We are confident that through the reform of Mandarin teaching and with the aid of daily intensive training, students can improve their language and expression and pass Mandarin proficiency test with ease. Furthermore, the overall Mandarin teaching level in Chinese colleges and universities will be raised.

\section{References}

[1] Wei Yujuan. On Aesthetic Dimensions of Mandarin Teaching. Jiangxi Social Sciences, 2013(05).

[2] Zeng Fang. Strategies to Improve Mandarin Proficiency of Normal Majors. Eduication Exploration, 2014(08).

[3] Bai Ying, Zhao Yuhong. Borrowing Approaches of Dialect in Mandarin Teaching and its Implication. Journal of Yangzhou Education College, 2011(04) .

[4] Li Jiaying. A Preliminary Research into Mandarin Teaching Reform in Colleges and Universities. Reform and Exploration, 2013(07).

[5] Zhou Hong, Luo Mingdong. Psychological Foundations of Mandarin Teaching. Journal of Yunan Normal University (philosophy and social sciences edition), 2013(04).

[6] Liu Ping. Improving Mandarin Teaching with Modern Education Technologies. Yichun College Journal, 2011(05). 